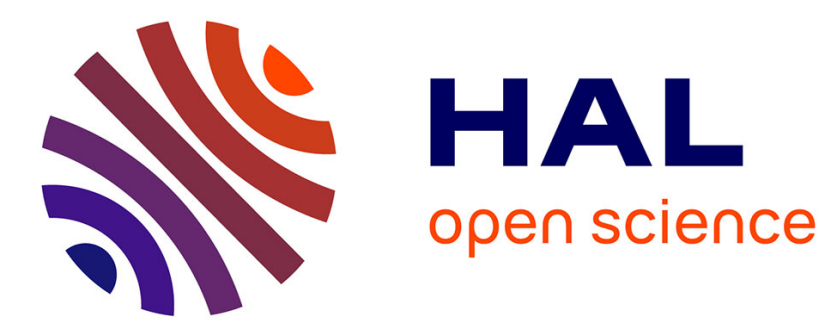

\title{
Comprehensive study of an optical fiber plasmonic microsensor in a microfluidic device
}

\author{
T. Makiabadi, V. Le Nader, M. Kanso, G. Louarn
}

\section{To cite this version:}

T. Makiabadi, V. Le Nader, M. Kanso, G. Louarn. Comprehensive study of an optical fiber plasmonic microsensor in a microfluidic device. European Physical Journal: Applied Physics, 2011, 56 (1), pp.13704. 10.1051/epjap/2011100223 . hal-00736284

\section{HAL Id: hal-00736284 \\ https://hal.science/hal-00736284}

Submitted on 28 Sep 2012

HAL is a multi-disciplinary open access archive for the deposit and dissemination of scientific research documents, whether they are published or not. The documents may come from teaching and research institutions in France or abroad, or from public or private research centers.
L'archive ouverte pluridisciplinaire HAL, est destinée au dépôt et à la diffusion de documents scientifiques de niveau recherche, publiés ou non, émanant des établissements d'enseignement et de recherche français ou étrangers, des laboratoires publics ou privés. 


\section{Comprehensive Study of an Optical Fiber Plasmonic Microsensor}

\section{in a Microfluidic device}

Tahereh Makiabadi, Victor Le Nader, Malak Kanso, and Guy Louarn

Institut des Matériaux Jean-Rouxel (IMN)CNRS, Université de Nantes

2 rue de la Houssinière B.P. 32229 F-44322 NANTES cedex 3

guy.louarn@cnrs-imn.fr

Received : date / Revised version : date

Résumé In the last decade, surface plasmon resonance (SPR) has become a very sensitive technique for real-time detection of chemical and biochemical targets in many application areas. Considering the important needs for analyzing biomolecular reactions through automated and miniaturized components, optical fiber sensors based on the SPR effects are presently considered as an alternative in the development of microsensors. In the present work, a microfluidic system associated with an optical fiber SPR sensor is developed and evaluated to monitor in real-time the sensitivity of optical fiber sensor to each kinetic reaction occurring at the surface. From the kinetic parameters obtained by our experimental measurements and then implemented in the numerical model, modeling allows us to demonstrate the potential of SPR optical fiber sensors for biological analysis.

KEYWORDS : SPR, surface plasmon, optical fiber sensor, microfluidic cell.

\section{Introduction}

Today, many microbiological analysis laboratories uses micro-device that integrates one or several functions, also named lab-on-a-chip. The success story of these systems is mainly due to their automation and miniaturization, which makes possible measurements with a single device, while analyzing and handling of samples very quickly. In biotechnology, these samples often consist of living organisms. In order to preserve the studied targets, it is important to be able to manage them in small volume of fluid flowing through channels with micrometer or nanometer 
dimensions. This manipulation of fluids is known under the term "microfluidics".

Mainly driven by the recent development of biotechnology, microfluidics has become an important sector in fluid mechanics, and research on "lab on a chip" and sensitive substrates progressing rapidly. This evolution is mainly due to strong demand for handling samples in small quantities, and then to increase the ratio "surface / volume" during surface chemical reactions. By this way, biosensors coupled with microfluidic devices make it possible to automate screening and then increase the capability to perform complex analysis on cellular or molecular entities $[1,2,3,4]$.

The objective of this work was to optimize the performance of an optical fiber sensor based on surface plasmon resonance $(\mathrm{SPR})$ in real operating conditions. To achieve this goal, it was necessary to develop a numerical model enabling us to determine the optimal operating conditions of the sensor. In order to evaluate appropriate values of parameters, an experimental set up was developed and from these experimental data, numerical simulations were carried out. This led us to study and to model (I) the flow and the transport of mass by diffusion and advection of target molecules inside a microfluidic cell; (II) the reactions of hybridization of target molecules with ligands grafted on the sensitive surface; (III) the sensitivity and the detection limit of our system.

\section{Experimental devices}

The microfluidic cell, designed for this study, is shown in Figure 1. It measures the optical responses of the sensor according to the flow and the concentration of the analyte versus time.

\subsection{Fiber sensors}

Multimode fibers FT-300-EMT (Thorlabs Inc) were used. These fibers have a silica core and a plastic cladding with diameters of 300 and $330 \mu \mathrm{m}$ respectively (numerical aperture NA : 0.39). Firstly, the optical cladding in Tefzel polymer was removed on two centimeters, on the central part of the fiber. Then this sensitive stripped area was carefully rinsed and cleaned with acetone.

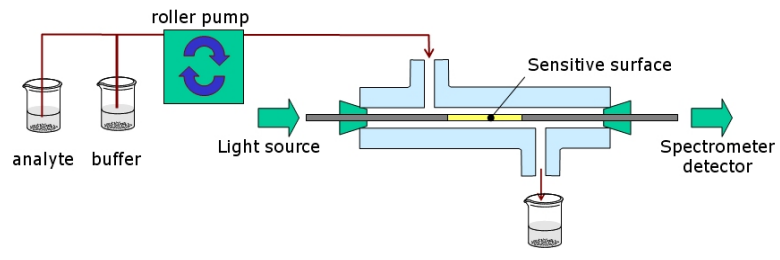

Figure 1. Sketch of the microfluidic cell used in this study

The fiber was cleaved at its two ends then a thin gold layer was deposited on the bare zone by thermal evaporation. To obtain a homogeneous film, we used a mechanical system coupled to a stepper motor that allows the rotation of fiber during the phase of metallization (see Figure 2). The rotational frequency of fiber was fixed to $0.5 \mathrm{~Hz}$. The evaporation of gold was carried out under a pressure of $6.10^{-6} \operatorname{mbar}[5]$.

The fiber was cleaved at its two ends then a layer of gold was deposited on the stripped zone by thermal evaporation. To obtain a homogeneous film, we used a mechanical system coupled to a step by step engine that allows 
the rotation of fiber during the phase of deposit (see Figure 2). The rotational frequency of fiber was $0.5 \mathrm{~Hz}$. The evaporation of gold was carried out under a pressure of approximately $6.10^{-6} \operatorname{mbar}[5]$.

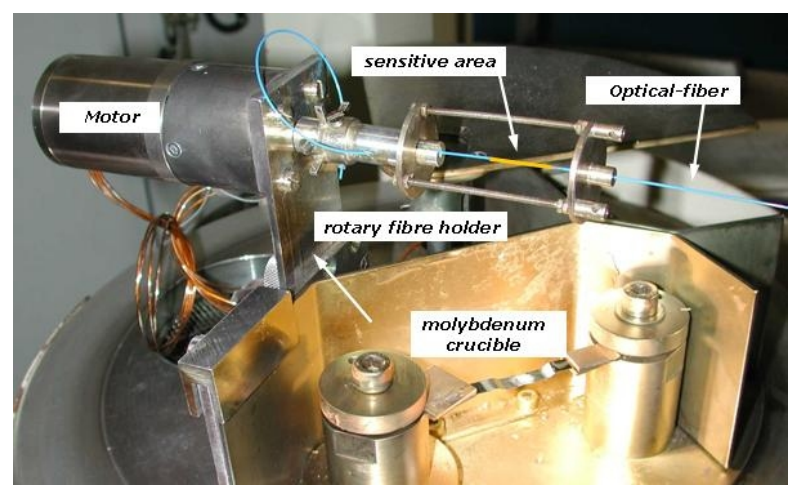

Figure 2. Image of the device allowing the rotation of the fiber in the glass bell-jar evaporator (Alcatel).

\subsection{Optical setup}

The experimental setup consists of a source of white light (halogen lamp, HL-2000, Mikropack) connected to the input of the optical fiber, fiber which crossing a capillary (microfluidic cell) where the solutions is injected. A miniature optical fiber spectrometer (Ocean Optics S2000) is connected on the output of the fiber in order to measure the light transmission through the fiber [6]. In this way, the response of the sensor versus to the wavelength of the input light (550 to $1100 \mathrm{~nm}$ ) can be recorded as a function of the hybridization of the analyte on the surface.

\subsection{Microfluidic cell}

The microfluidic system consists of a roller pump, channels with an internal diameter of $1 \mathrm{~mm}$, and a cell crossed by the optical fiber sensor where the expected hybridization occur on the gold surface during the flow of the analyte. The cylindrical glass cell (capillary) (1mm of internal diameter) is sufficiently wide to receive the optical fiber with a core diameter of ranging between $300 \mu \mathrm{m}$ and $400 \mu \mathrm{m}$. The cylindrical form allows a homogeneous circulation of the analyte around the fiber. This cell, of $5 \mathrm{~cm}$ length, has a volume of about $40 \mu \mathrm{L}$.

\section{Experimental Results and modeling}

From SPR effect, the hybridization of target molecules on the surface induces a variation of the optical transmission in the optical fiber $[5,6,7,8]$. As a result of this hybridization, a gradient of concentration of the target molecules is created in an area near the surface of the fiber, known as "concentration boundary layer" (figure 3). Then, diffusion phenomena emerge, which are modulated by the circulation of analyte. Quickly, equilibrium of concentrations near the surface is put in place, which is visualized by the curves called sensorgrams (see Figure 5).

Practically, the biological targets are diluted in a liquid (buffer solution) to be guided towards the reactive surface where they are immobilized during the time of measurement. Then, various forces operate on these targets. In a microscopic scale, we have to take into account the diffusion effect, which describe the natural, rapid and random movement of the particles (Brownian motion), the advection effect (forced convection) of the particles in the moving fluid, and mechanisms of hybridization (i.e. ad- 
sorption and desorption) of the particles on the surface of the sensor.

Chemical surface reactions, as the phenomena of adsorption and desorption (hybridization for instance), are often taken into account by using the Langmuir model. Finally, all these phenomena (diffusion - advection, adsorption and desorption) are implemented in our numerical model to simulate the light transmission through optical fiber by SPR effect $[9,10,11]$.
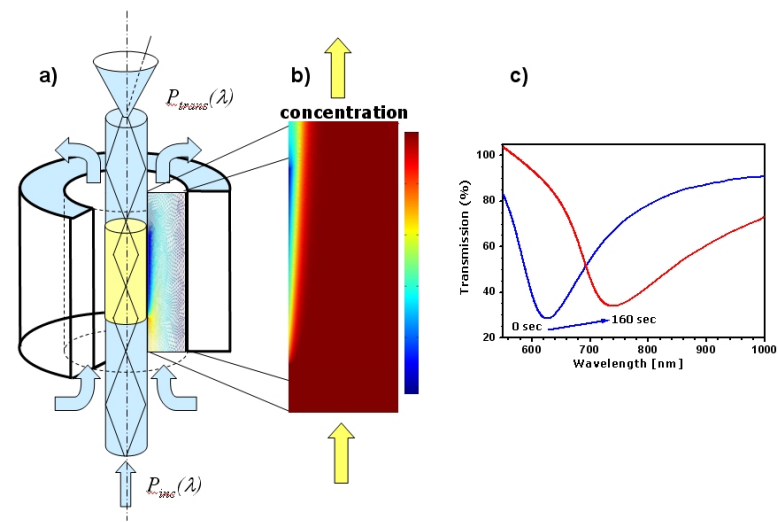

Figure 3. a ) sketch of the microfluidic cell, b) gradient of the concentration of analyte near the active surface so called "concentration boundary layer" (modeling obtained from finite elements analysis) c) optical transmission through the fiber. Examples of Curves registered before and during hybridization at the active surface.

\subsection{Modeling of optical response of the SPR sensor}

In order to model the experiments, calculation of the optical transmission had to be coupled to the mass transport. The equations used to solve the liquid circulation in a microfluidic system, generally derived from the Navier-
Stokes equations, are associated with simplifying assumptions, particularly about the geometry of the channels. To resolve the partial derivative equations (PDEs) and for the discretization of space, the Comsol Multiphysics software (version 3.5) was used. The coupling with the optical measurements was implemented under Matlab 7. Figure 4 presents the experimental and simulation curves of the light transmission at $600 \mathrm{~nm}$ versus time (injection of a water/glycerol solution).

The experimental results are compared with the numerical results in order to validate the simplifying assumptions which are introduced to the modeling the flow phenomena. The optical effects induced by surface plasmon resonance SPR and the partial derivative equations representing mass transport of analytes were calculated simultaneously, taking into account the geometry of the cell. In this configuration, the channels had a dimension of approximately $300 \mu \mathrm{m}$ and the speed of the circulation $\mathrm{U}$ of analytes was about 1 to $50 \mathrm{~mm} / \mathrm{sec}$. At these scales, turbulence is absent in our microfluidic system, the flows to be modeled are laminar, and the fluids are incompressible, homogeneous and Newtonian [12].

\subsection{Biochemical reaction and Langmuir model}

Basically, the objective of a SPR sensor, and more generally of a biochip, is the analysis and recognition of target macromolecules (DNA, proteins, etc). The bio-recognition can be based on a mechanism called "key-lock". Biomolecular reaction can be described as the association of two molecules forming a "complex", such as two comple- 

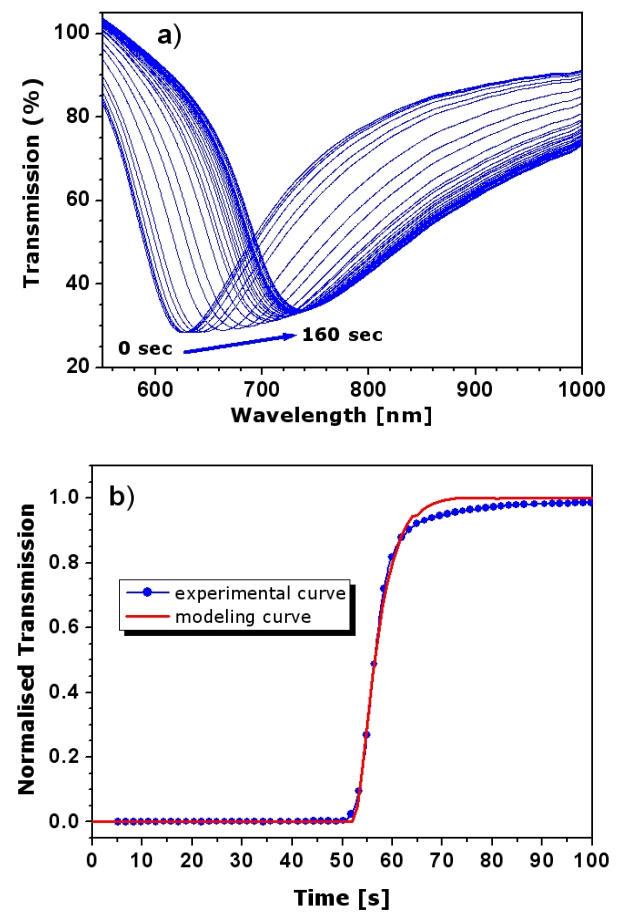

Figure 4. a) experimental responses (light transmission) of optical fiber SPR sensor during the injection of a glycerol/water solution $(\mathrm{nS}=1.3820) ; \mathrm{b})$ optical response measured at 600 $\mathrm{nm}$ (fluid velocity $\mathrm{U}=10 \mathrm{~mm} / \mathrm{s}$; diffusion coefficient $\mathrm{D}=10^{-9}$ $\mathrm{m}^{2} / \mathrm{s}$; concentration of glycerol/water solution $\left.\mathrm{C}_{0}=5,43 \mathrm{M}\right)$.

mentary single stranded DNA $[13,14,15,16]$. Among the various models of heterogeneous molecular reactions, we have chosen to implement the Langmuir model. This model uses the concepts of association and/or dissociation of complex on the surface that determine the affinity of a ligand (L) for an analyte (A).

In a microfluidic cell, the analyte is transported towards the surface by convection and diffusion, as it is injected in continuous flow. The ligand-analyte reaction, especially its kinetics, depends not only on the reaction rates on the surface but also on the processes of mass transport near to the surface. The rate of the adsorption is calculated by solving simultaneously the following equations :

$$
\frac{d \Gamma}{d t}=k_{a s s} C_{\text {surf }} \times\left(\Gamma_{0}-\Gamma\right)-k_{\text {diss }} \times \Gamma
$$

Where $\Gamma$ is the concentration of the immobilized analytes, $\Gamma_{0}$ is the initial concentration in available hybridization sites, $\mathrm{k}_{\text {ass }}$ is the absorption coefficient at the surface, $\mathrm{k}_{\text {diss }}$ is the desorption coefficient at the surface and $\mathrm{C}_{\text {surf }}$ is the concentration of the analyte close to the surface. here, the coupling between the surface reaction and the transport mechanisms appears via $\mathrm{C}_{\text {surf }}$.

To determine the concentration $\mathrm{C}_{\text {surf }}$, the balance of the masses on the surface should be introduced, taking into account the depletion of concentration of target molecules near the surface. In this way, the mechanism of advection-diffusion was used (buffer fluid flowing through the microchamber). Concentration and gradient of concentration in the fluid was obtained by solving the usual advection-diffusion equation :

$$
\frac{\partial C}{\partial t}=\nabla \cdot(D \nabla C-C v)
$$

Where $\mathrm{C}$ is the concentration of analytes, $\mathrm{D}$ is its diffusion coefficient, and $\mathrm{v}$ is the flow velocity. The equations 1 and 2 are not independent. The coupling between the two equations is realized by Fick'law : 


$$
\frac{d \Gamma}{d t}=-\left.D \nabla C\right|_{\text {surf }}
$$

Then, the surface concentration of hybridized targets can be computed as a function of the analyte concentration near the surface, using Equation 4 :

$$
\Gamma=\frac{\left.D \nabla C\right|_{\text {surf }}+k_{a s s} C_{\text {surf } f} \Gamma_{0}}{k_{a s s} C_{s u r f}+k_{d i s s}}
$$

Concerning the boundary condition at the active surface, the rate of the reaction at the surface is balanced with the flow of the analyte and the concentration of the adsorbed species as described by the following equation :

$$
\text { n. }(-D \nabla C+C v)=-k_{a s s} C_{s u r f}\left(\Gamma_{0}-\Gamma\right)+k_{d i s s} \Gamma
$$

\subsection{Kinetic study of the PKI-PrKX reaction}

Taking into account the ligand-analyte interaction (formation of the organic layer) in our numerical model requires the introduction of the values of kinetic parameters (kass et kdiss). These parameters contribute to describe the boundary condition and the molecular response to the sensible area. For this, we used the experimental results obtained by B. Zimmermann et al. [17].
Figure 5 a) shows the experimental sensorgrams of the PKI protein (protein kinase inhibitor) immobilized on the sensitive surface, and PrKX protein (human X chromosome protein kinase) as analyte. From this study, values needed for our numerical model should be extracted, and numerical investigations of the SPR response of optical fiber SPR sensor were performed. Particularly, values of kass and kdiss were extracted from these curves and modeling were performed with $3.810^{5} \mathrm{M}^{-1} \mathrm{~s}^{-1}$ et $5.810^{-3}$ $\mathrm{s}^{-1}$ respectively.
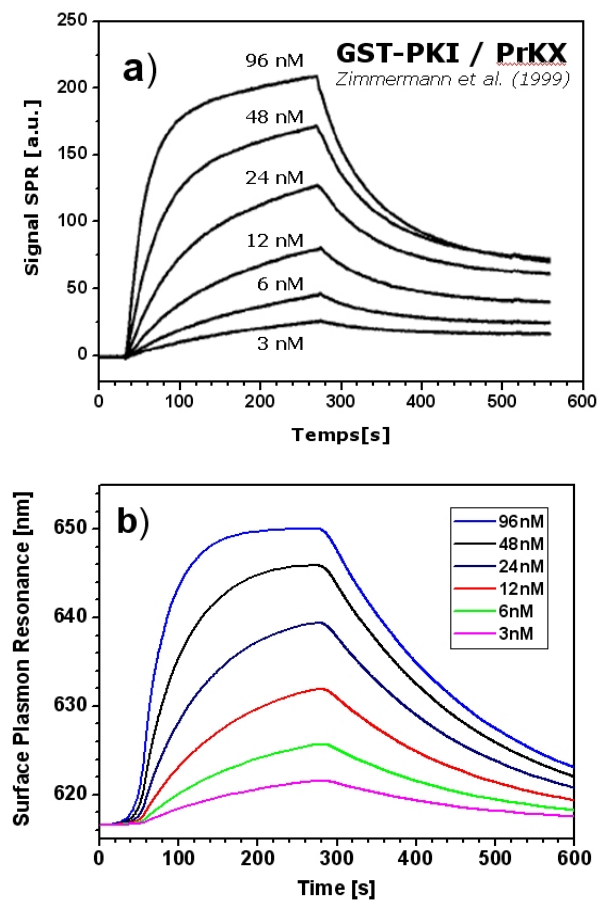

Figure 5. a) experimental SPR response of hybridization of the protein PKI (Ligand) with the protein Kinase X (analyte) versus time (according to Zimmermann and al. [17]). b) : theoretical evaluation of the SPR response versus time and as a function of the analyte concentration (protein PKI with the protein Kinase X; U=6 mm/s; D $=10^{-10} \mathrm{~m}^{2} / \mathrm{s} ; \mathrm{k}_{a s s}=3.8$ $10^{5} \mathrm{M}^{-1} \mathrm{~s}^{-1}$ and $\mathrm{k}_{\text {diss }}=5.810^{-3} \mathrm{~s}^{-1}$ ). 
From the curves presented Figure 5b, the best sensitivity of our optical fiber SPR sensor was evaluated and the value of $1.7 \mathrm{~nm} / \mathrm{nM}$ was found. This value was obtained from the linear part of the response curves, in the 0 to $10 \mathrm{nM}$ concentration range. The smallest wavelength shift that can be detected with the spectrometer used in this study was $1 \mathrm{~nm}$. In consequence, the concentration detection limit can be estimated to $1.7 \mathrm{nM}$. From this uncertainty, a mass detection limit of $12 \mathrm{ng}$ has been determinated from the concentration detection limit (equivalent mass for a biological layer of $20 \mathrm{~nm}$ thick).

\section{Conclusion}

In this work, responses of an optical fiber SPR sensor were studied with the presence of an analyte subjected to a laminar flow. This flow was carried out in a microfluidic cell, where the fiber sensor is placed. The main goal of this study was to evaluate the effectiveness and the sensitivity of this sensor in an actual operational configuration.

The molecular interaction of PKI protein with PrKX protein was used as a model. A sensor sensitivity of 1.7 $\mathrm{nm} / \mathrm{nM}$ was determined, and a mass detection limit of about 12 ng. In conclusion, this work revealed that an optical fiber SPR sensor coupled to a microfluidic cell, is able to perform biological analysis, whether quantitative or qualitative.

\section{Références}

1. Berthier J. and Silberzan P., Microfluidics for biotechnologie (Artech House, Boston/London 2006) p. 177

2. Minc N.and Viovy J.L., comptes rendus physique 5, (2004) p. $565-575$.

3. Huang S. C., Lee G. B., Chien F. C., Chen S. J., Chen W. J. and Yang M. C., J. Micromech. Microeng. 16, (2006) p.1251-1257.

4. Wang Y., Vaidaya B., Farquar H. D., Stryjewski W., Hammer R. P., McCarley R. L. and Soper S. A., Anal. chem 73, (2003) p. $1130-1140$.

5. Balaa K., Kanso M., Cuenot S., Minea T., Louarn G., Sensors and Actuators B : Chemical 126, (2007) p. 198-203.

6. Kanso M., Cuenot S., Louarn G., Plasmonics 3, (2008) p. $49-57$.

7. Homola J., Analytical Bioanalytical Chemistry 377, (2003) p. $528-539$.

8. Gupta B. D. and Sharma A. K., sensors and actuators B 107, (2007) p. 40-46.

9. ] Myszka D. G. and Norton T. A., Trends Biochem. Sci. 23, (1998) p. $149-150$.

10. Karlsson R., Katsamba P. S., Nordin H., Pol E. and Myszka D. G., Analytical Biochemistry 349, (2006) p. 136147.

11. Gervais T. and Tensen K. F., Chemical Engineering Science 61, (2006) p. 1102-1121.

12. William B. and Zimmerman J., Process Modelling and simulation with finite element methods : Series on stability (World Scientific, Singapore 2004) p. 182

13. Tsoi P. Y. and Yang, M., Biochem. J. 361, (2002) p. 317. 
8 Tahereh Makiabadi et al.: Comprehensive Study of an Optical Fiber Plasmonic Microsensor in a Microfluidic device

14. GlasserR. W., Analytical Biochemistry 213, (1993) p.152-

161.

15. Christensen L. L., Analytical Biochemistry 249, (1997)

p.153-164.

16. Karlsson R. and Falt A., J. Immunol. Methods 200, (1997)

p.121-133.

17. Zimmermann B., Chiorinis J. A., Ma Y. and Kotin R. M.,

The journal of biological chemistry 274, (1999) p. 5370-5378. 